\title{
Encontros Burocráticos e Suas Reverberações Simbólicas: uma exploração das EXPERIÊNCIAS DE INTERAÇÃO COTIDIANA COM AGENTES DO ESTADO $0^{1,2}$
}

\author{
Roberto Rocha C. Pires ${ }^{3}$
}

\begin{abstract}
"É muito humilhante, você ficar ali, um monte de gente, logo cedo, pra chegar certa hora pra dizerem que o médico não veio"
(Entrevista com E., apresentada no caso 2).

"Eram pessoas que moravam em barraco, como eu estou Ihe dizendo (...) Construíram, deram casa, deram apartamento, tá entendendo? Eu acho isso bonito. Eu acho bonito, é um trabalho muito bem feito" (Entrevista com 0., apresentada no caso 5)
\end{abstract}

\section{INTRODUÇÃO}

Humilhação, demora, desamparo. Acolhimento e exercício de direitos. Os encontros cotidianos das pessoas com os serviços prestados pelo poder público repercutem em experiências e sentimentos diversos, tal como expressos por aqueles que, no âmbito do projeto Radiografia do Brasil Contemporâneo, relataram seus envolvimentos com o Estado e seus agentes.

Este artigo pretende apresentar os resultados iniciais de um estudo em andamento que toma como objeto central os encontros burocráticos. Isto é, os momentos e situaçóes - vividos diretamente pelos sujeitos ou narrados a partir das experiências vividas por outrem - em que pessoas interagem com funcionários do governo - servidores públicos ou aqueles que os representem - em busca de algum benefício, serviço ou atendimento previsto em lei ou diretriz governamental (Kahn, Katz e Gutek, 1976; Goodsell, 1981; Hasenfeld, 1985; Hasenfeld, Rafferty e Zald, 1987).

Encontros burocráticos são eventos que abundam nas trajetórias das pessoas em sociedades modernas, uma vez que, do nascimento à morte, o processo de construção social do sujeito é mediado por operações de registro, ordenamento, classificação e prestação de serviços voluntários (e.g., acesso à saúde) e involuntários (e.g., tributação e segurança pública) desempenhados ordinariamente por agentes estatais.

A esses encontros burocráticos cotidianos podemos atribuir uma eficácia simbólica e representacional com pelo menos duas reverberaçôes. A primeira diz respeito aos efeitos de subjetivaçáo dos encontros burocráticos cotidianos. Tal como nos alertou Hasenfeld (1972), as organizaçôes governamentais são, eminentemente, "processadoras de pessoas" e têm papel-chave na atribuiçáo de status público aos seus usuários, com potenciais repercussóes no deslocamento ou na estabilização de situaçôes e identidades sociais. Assim, as diferentes experiências de encontro burocrático podem se tornar decisivas na constituição de um sentido de pertença, interferindo nos processos de construção de uma definiçáo pelos próprios sujeitos sobre o valor que têm, o lugar e a posição que ocupam no espaço social.

1. 0 autor agradece a Marco Natalino, Daniel Avelino e Frederico Barbosa pela leitura e pelos comentários que contribuíram para o aprimoramento deste texto.

2. DOI: http://dx.doi.org/10.38116/bapi23art3

3. Técnico de planejamento e pesquisa na Diretoria de Estudos e Políticas do Estado, das Instituições e da Democracia (Diest) do Ipea. 
A segunda reverberação desses encontros, por sua vez, impóe-se sobre as representações e a construção de definiçốes para noçôes tão abstratas como Estado, políticas públicas e cidadania, as quais passam a adquirir um sentido prático para os diferentes sujeitos, tanto como esfera de exercício de direitos, concessáo de favores ou reproduçáo de desigualdades. Sharma e Gupta (2006) nos relembram de tratar o Estado como um artefato cultural complexo, impossível de ser percebido em sua totalidade - mas que é encontrado e ganha existência concreta de forma fragmentada por meio dos encontros cotidianos com burocratas e suas agências, que lhe dão corpo mediante suas práticas e discursos. Os encontros burocráticos adquirem, assim, uma eficácia representacional na construção de uma imagem do Estado, para além de eventos extraordinários. Assim, esses encontros, e como eles são experimentados, alimentam perspectivas sobre o vínculo (e.g., pertencimento ou desamparo) de um sujeito com a comunidade política na qual se encontra.

Elias (1994) descreveu as ligaçôes entre os indivíduos e o Estado como cadeias de interdependência que provêm recursos materiais e simbólicos aos indivíduos, "interferindo também na identificação que estes indivíduos constroem com um 'nós' coletivo".

Siblot (2006), por sua vez, propóe que os serviços públicos sejam compreendidos como elos dessas cadeias. Assim, os encontros burocráticos que concretizam a provisão de serviços no cotidiano estariam no centro de um processo político-moral que entrelaça as representaçóes que os sujeitos formam sobre as instituiçôes públicas e o reconhecimento social que as instituiçóes públicas formam sobre esses sujeitos.

Nesse sentido, o estudo em andamento vem se orientando por algumas questóes. Quais são as principais diferenças nas formas como sujeitos em diferentes situaçóes e trajetórias sociais experimentam cotidianamente o Estado brasileiro? Como essas diferentes formas de experiência afetam a leitura que esses sujeitos fazem sobre a sua situação social e a construção de representações e sentidos para noções tão abstratas como Estado, política pública e cidadania?

A base de dados produzida pelo projeto Radiografia do Brasil Contemporâneo ${ }^{4}$ oferece uma oportunidade única para esse tipo de exploração. São 632 entrevistas biográficas em profundidade, com pessoas residentes em todas as regióes do Brasil e com trajetórias e posiçóes sociais distintas. Para além da caracterização da posição e da trajetória social dos respondentes, as entrevistas foram, em parte, dedicadas a obter relatos sobre suas percepçóes e relações com distintos serviços públicos oferecidos pelos governos no Brasil, como o Sistema Único de Saúde (SUS), as políticas de educação e segurança pública, além de programas governamentais específicos, como o Programa Bolsa Família, o Minha Casa Minha Vida e o Programa Nacional de Acesso ao Ensino Técnico e Emprego (Pronatec), por exemplo. Assim, dado o seu caráter biográfico, essas entrevistas permitem acesso aos processos de constituição dos vínculos práticos e políticos entre pessoas e instituições da esfera estatal.

O estudo pretende caminhar no sentido da análise sistemática da totalidade das entrevistas produzidas pelo projeto, buscando: i) categorizar as diferentes trajetórias e posiçóes sociais dos respondentes, utilizando variáveis, escalas e categorias referentes à segmentação da amostra em termos de classes sociais (isto é, renda, ocupação, escolaridade etc.); ii) identificar, a partir das narrativas, as diferentes modalidades de experiência de interação com Estado na provisão de serviços diversos, como saúde, educação, assistência social, segurança pública, moradia etc.; e iii) explorar as associaçóes entre as diferentes trajetórias sociais

4. Mais informações sobre o referido projeto podem ser obtidas no artigo introdutório deste BAPI. 
e as modalidades de experiência de interação com os agentes e os processos estatais. Acredita-se que os resultados a ser produzidos permitirão uma compreensão empiricamente fundamentada dos diferentes efeitos dos encontros burocráticos cotidianos, amparando reflexóes sobre a reorganização e efetividade dos serviços públicos no combate à desigualdade social no Brasil.

Por se tratar de estudo ainda em andamento, este texto se restringe, em um primeiro momento, a apresentar o referencial teórico que dará suporte às reflexóes empíricas e, em seguida, relatar os resultados de uma análise exploratória inicial, a partir de uma pequena amostra entre o conjunto das entrevistas disponíveis. Trata-se de uma exploraçáo-piloto, teoricamente orientada, das relaçóes entre trajetórias sociais e experiências de encontro burocrático.

\section{ENCONTROS BUROCRÁTICOS E A SOCIOLOGIA DO GUICHÊ5}

A sociologia do guichê nomeia um conjunto de estudos que começaram a emergir na França a partir de meados da década de 1990. Trata-se de análises que visaram compreender o "Estado em ação" (Jobert e Muller, 1987) e se debruçaram sobre os guichês dos serviços públicos, em áreas tão diversas quanto assistência e seguridade sociais, habitação, imigração, segurança pública, serviços postais, financeiros e cartoriais. Os guichês instanciam fronteiras e liminaridades. São fundamentalmente encontros - físicos ou virtuais e que prescindem do típico balcão/janela - entre cidadãos, usuários ou beneficiários de serviços, de um lado, e funcionários, burocratas e representantes do Estado, de outro.

Para a administração, o guichê é uma abertura para o exterior, espaço da concretização de abstratos desideratos políticos e legais. Para o cidadão, ou usuário dos serviços, o guichê traz a personificação da instituição pública, por meio do qual se desdobrarão diálogos e trocas específicas sobre a sua situação. O guichê produz lugar, visibilidade e escuta. É nele que as situaçôes sociais ganham corpo, rosto e voz. Em função dessas características, o guichê passou a ser reconhecido como local estratégico para a compreensão dos encontros burocráticos.

Aos poucos, a sociologia do guichê começa a ganhar contornos. Ela é tributária da confluência do desdobramento das reformas de modernização do serviço público, implementadas a partir do final da década de 1980, com os aportes teóricos da sociologia da administração francesa (Crozier, 1963; Friedberg, 1972; Thoenig, 1973; Crozier e Friedberg, 1977; Dupuy e Thoenig, 1983) e do interacionismo simbólico norte-americano (Goffman, 1961; Herbert, 1969; Hughes, 1971). Uma das vertentes dessa literatura, inaugurada a partir do trabalho de Dubois (1999), passou a se distinguir pela incorporação de insights, conceitos e abordagens da sociologia crítica de Pierre Bourdieu. Os trabalhos que se sucederam começaram a dar corpo ao que poderíamos chamar de um interacionismo crítico, no qual os encontros burocráticos nos guichês passaram a ser explorados como dispositivos de governo, de regulação de populações administradas e dominação social (Dubois, 1999; Siblot, 2006; Spire, 2008).

Seguindo os passos de Bourdieu (1972), segundo o qual a verdade da interação nunca reside inteiramente dentro da própria interação, os autores dessa vertente passaram a insistir na restituição das interaçóes no guichê ao conjunto das relaçóes sociais dentro das quais elas se inserem. Isto é, em reflexóes apoiadas na análise dos efeitos das características sociais dos usuários e dos burocratas sobre as relaçóes que se formam entre eles. Assim, os encontros no guichê passaram a ser entendidos como influenciados por relaçóes de classe e produtores de efeitos sociais sobre os usuários dos serviços, atuando como uma forma de violência simbólica e resultando na reprodução de desigualdades.

5. Esta seção é baseada em Pires (2017), em que se apresenta uma revisão sistemática da literatura francesa em torno da sociologia do guichê. 
O trabalho pioneiro de Dubois (1999) enfatizou a natureza estruturalmente assimétrica dos encontros burocráticos, sublinhando as implicaçóes políticas e morais sobre os usuários dos serviços e dando maior centralidade às reflexôes sobre poder e dominação. Segundo o autor, em um contexto de assimetria, as interaçôes supostamente administrativas que se desenrolam no guichê adquirem um caráter normativo, pois "a mera aplicação de categorias administrativas se torna uma atribuição de status, e a apreensão da relação administrativa equivale a uma reapreensão das normas da vida social” (Dubois, 1999, p. 138, tradução nossa).

Entre os trabalhos da sociologia do guichê, no entanto, é Siblot (2006) que oferece os referenciais mais adequados para se pensar os efeitos dos encontros burocráticos sobre as representaçóes sociais que as pessoas constroem sobre si e sobre o Estado e suas políticas públicas. Por meio do estudo de trajetórias biográficas individuais e familiares de usuários de diferentes serviços, residentes em um mesmo bairro popular da periferia parisiense, a autora argumenta que as diferentes relaçóes estabelecidas com as instituiçóes públicas prestadoras de serviços podem ser decisivas na constituição de um sentido de lugar social para esses indivíduos. A razão disso é que essas relações têm desdobramentos tanto materiais quanto simbólicos para uma leitura que os usuários fazem sobre a sua localização no espaço social. Na seção seguinte, buscaremos aproximar as reflexóes e conclusóes das análises de Siblot (2006) com as entrevistas produzidas no âmbito do projeto Radiografia do Brasil Contemporâneo.

\section{TRAJETÓRIAS E POSIÇÕES SOCIAIS E AS REPRESENTAÇÕES DOS ENCONTROS BUROCRÁTICOS NA RADIOGRAFIA DO BRASIL CONTEMPORÂNEO}

A partir da análise das trajetórias biográficas dos usuários de serviços, Siblot (2006) identificou, entre uma diversidade de situaçóes analisadas, quatro formas mais comuns que operavam a construção de vínculos práticos e políticos entre usuários e instituiçốes provedoras dos serviços. A seguir, vamos relacionar essas quatro formas observadas pela autora (descritas em cada uma das subseçóes seguintes) com amostras ilustrativas do material produzido por meio de entrevistas para o caso brasileiro.

\subsection{Distanciamento e despeito}

A primeira forma de vínculo se refere a uma relação distanciada da administração, tipicamente estabelecida por famílias situadas mais próximas à classe média (seja logo abaixo ou logo acima). Enquanto, em alguns desses casos, a experiência de distanciamento adquire um tom eufemístico e benevolente, em outros casos, o distanciamento toma forma de um despeito em relação aos serviços assistenciais oferecidos pelo sistema público, alimentando um desprezo social em relação aos estratos mais precários que deles se utilizam (Siblot, 2006).

Os dois casos que serão apresentados dizem respeito a pessoas em situações próximas à classe média: ${ }^{6}$ um pequeno empresário e uma ascendente à dita nova classe média. Os casos parecem indicar que a condição de proximidade com a classe média pode estar associada a um esforço de distanciamento e independência em relação às ofertas públicas, as quais são descritas como decadentes, deprimentes e indignas.

6. A categorização dos entrevistados em termos de classe social empregada neste estudo se baseou nas escalas construídas pela equipe do projeto Radiografia do Brasil Contemporâneo e em elementos encontrados nas próprias entrevistas (como autoclassificação, situação de renda, moradia etc.). 


\section{Caso 1}

H. é sócio de um pequeno estúdio de fotografia no centro da cidade. Teve uma trajetória estável e não marcada por carências ou precariedades. Começou a trabalhar aos 18 anos, na banca de revistas do pai, para juntar dinheiro, pois desejava ser músico. Posteriormente, estudou jornalismo, embora não tenha concluído o curso.

Entrevistador: "Como é a sua relação com o SUS?"

Entrevistado: "Minha relação com o SUS é quase zero. Minha vida inteira tive plano de saúde. Até que meu avô faleceu e não pagou mais o plano. Aí eu comecei a pagar. No começo do estúdio, que a gente teve de investir grana, eu parei de pagar. Quando fui fazer cirurgia, tinha trocado o plano de saúde, e aí eu ia ter de, talvez, fazer no SUS com o mesmo médico que me operou, porque ele é diretor do hospital (...). Mas ele preferiu esperar seis meses para fazer a cirurgia do que fazer no SUS. Não pela cirurgia em si. Mas pelo pós-operatório, que seria numa cama de hospital melhor, com ar-condicionado, alimentação melhor, do que no hospital público.”

Entrevistador: "Como é que você avalia o SUS?"

Entrevistado: "Eu avalio como um local deprimente, sem qualquer condição de você ir para lá e ser atendido honestamente."

(...)

Entrevistador: "Como é que você avalia o Pronatec?"

Entrevistado: "Eu acho que é bom. Mas é como se rebaixasse o cara negro e pobre, ou branco e pobre, a só ter um curso técnico. Ele se satisfaria com aquilo e não iria querer fazer uma faculdade. Acho legal, mas acho que ainda é como se fosse mais uma muleta. Você vai chegar até aqui, daqui você não passa."

\section{Caso 2}

E. teve uma infância pobre e uma história de vida sofrida e repleta de idas e vindas em casas de parentes e cônjuges. Quando entrevistada, em função do trabalho como frentista e cabelereira, percebia-se em um momento de ascensão, podendo morar em um bairro tradicional e movimentado da cidade, próximo à rodoviária e aos seus locais de trabalho. Além da pesada rotina, é frequentadora assídua da sua igreja.

Entrevistador: "Em relação ao SUS, o sistema de saúde, você o utiliza?"

Entrevistado: "Não."

Entrevistador: "Você tem plano [de saúde]?"

Entrevistado: "Não, não tenho plano. Simplesmente, quando acontece alguma coisa, eu levo no médico, num médico qualquer, consulto e pronto."

Entrevistador: "Então você não usa o SUS?"

Entrevistado: "Não." 
Entrevistador: "Mas por quê?"

Entrevistado: "Porque eu não tenho tempo pra ficar em fila [tom de riso], e eu acho muito demorado, eu acho humilhante... sério, sem brincadeira nenhuma... assim... quem sou eu na fila do SUS? [Tom de riso.] Mas eu acho muito humilhante, tem gente que chega logo cedo, começa não sei que horas, fora que eu não tenho tempo pra isso. Fora essa humilhaçáo, é muito 'demoroso'."

Entrevistador: "O que seria esse constrangimento?"

Entrevistado: “Tipo, você chega lá e são tantas fichas, nossa, você não pode nem questionar nada, porque, né? Acontece que são tantas fichas. É muito humilhante, você ficar ali, um monte de gente, logo cedo, pra chegar certa hora pra dizerem que o médico não veio. Entendeu? Não, não, não. É muito humilhante.”

O caso 1 envolve o relato de uma pessoa que, em virtude da capacidade de acessar recursos por meio do trabalho ou da família, possui opçóes e procura evitar sempre que possível a situação de beneficiário do serviço público, como o fez no caso da cirurgia. A situação de beneficiário é associada a um rebaixamento ou algo limitador, como expresso em sua avaliação sobre o Pronatec. Já o caso 2 aponta para uma trajetória de ascensão por meio do esforço próprio e do trabalho. Aqui, sendo as opçóes não tão fartas como no caso anterior (E. não possui plano de saúde nem apoio financeiro de familiares), o esforço de se distanciar e se diferenciar das ofertas públicas se torna ainda mais saliente. $\mathrm{O}$ encontro burocrático é descrito e sentido como algo humilhante, devido às filas e à excessiva demora impostas pelo serviço. Assim, precisa ser evitado, ainda que isso repercuta em custos adicionais. Isto é, o desejo de se distanciar e se perceber em uma situação distinta daquela associada ao público das ofertas públicas parece ser grande o suficiente para compensar os eventuais custos e riscos.

\subsection{Rebaixamento e decadência social}

A segunda forma por meio da qual os vínculos práticos e políticos são construídos, segundo Siblot (2006), envolve as famílias antes estáveis mas que se encontram em vias de desestabilização. Para tais famílias, a relação com serviços e políticas públicas equivale à revelação ou consolidação de um sentimento de perda e rebaixamento. Os relatos de dificuldades na interação com as agências e as decepçóes delas decorrentes se associam, de acordo com a autora, a uma experiência de queda e decadência social, traduzindo-se em uma desconfiança em relação às instituiçôes e às políticas públicas do cuidado social.

A situação que será relatada no caso 3 se destaca em relação aos casos anteriores por se tratar de uma trajetória descendente a partir de uma posição de classe média. Nesse caso, o reconhecimento de uma tendência à vulnerabilidade e à precarização ainda esbarra em uma postura de buscar o distanciamento da condição de beneficiário. Mesmo problematizando a desigualdade e as relações de classe no país, o entrevistado busca evitar a sua entrada na categoria usuário/beneficiário. Porém, nesse caso, para além de ser algo limitador ou humilhante, a condição de beneficiário de políticas públicas encontra-se fortemente associada à perda de dignidade e autonomia e à confirmação da queda.

Caso 3

I. é jornalista. Já trabalhou como repórter em redaçóes de grandes jornais, mas no momento vive de pequenos bicos e trabalhos esporádicos de consultoria em comunicação. Apesar do ampliado capital cultural pessoal e familiar (suas irmãs são professoras de história, e a família tem orgulho da sua coleção 
de livros e discos), vive uma situação econômica bastante instável. Divorciado e pai de um adolescente, recebe ajudas ocasionais de familiares para poder se manter.

Entrevistador: "Você já foi beneficiado por alguns desses programas [listados anteriormente]?"

Entrevistado: "Não, nunca, mas eu acho que há um fosso, um abismo tão grande entre as classes, né? Assim, quem tá lá em cima não sabe como é que é a vida dessas pessoas. E tratam de uma forma que... nossa... dá vergonha. Então, há sim a necessidade dessa assistência, de tratar as pessoas de forma digna, né? Com saúde, com educação. A gente viu aí vários vídeos de como os médicos... alguns médicos, não vou dizer que é a classe toda... mas a gente vê como eles tratam o povo, né? Como se não fosse nada, né? A gente vê muita coisa, mas eu acho que sim, acho que tem que ter [assistência], se tiver falha, se tiver alguma coisa, aí conserta."

Entrevistador: "Por que não recorrer a programas sociais, como o Minha Casa Minha Vida, já que você não possui uma casa própria? Isso te ajudaria?”

Entrevistado: "Como eu disse, o dinheiro não é o mais importante, cara. Quero o suficiente para me organizar. Estou bem aqui, navego sozinho no mundo, estou acostumado aqui."

Os três casos apresentados parecem ilustrar - algo que ainda precisa ser explorado em maior profundidade - que trajetórias associadas à classe média (estabilidade, ascensão ou decadência) carregam elementos pertinentes às duas primeiras formas de vinculação identificadas por Siblot (2006): distanciamento, despeito e desprezo às ofertas públicas, uma vez que representariam situações de desconforto, limitação, humilhação e declínio social. Além disso, esses três casos suscitam a hipótese, já desenvolvida em outros estudos, ${ }^{7}$ de que pessoas com esse tipo de trajetória social e que não utilizam cotidianamente os serviços públicos tendem a desenvolver uma avaliação mais negativa deles, em comparação com usuários recorrentes, como veremos a seguir.

\subsection{Estabilidade, expertise e demanda por serviços públicos}

Há ainda uma terceira forma de construção de vínculos que toca as famílias pobres em situação estável, ainda que eventualmente submetidas a maiores riscos e vulnerabilidades. Como observou Siblot (2006), famílias com esse tipo de trajetória e posição social tendem a desenvolver um uso positivo dos encontros burocráticos. A partir do uso recorrente dos serviços e benefícios públicos, elas adquirem uma expertise na condução das relaçóes administrativas, demostrando habilidade de recorrer aos recursos materiais e simbólicos de que necessitam para o seu bem-estar, especialmente como forma de evitar as ameaças eminentes de empobrecimento e precarização.

7. Tal como concluíram Piola et al. (2011, p. 86-87), "na opinião de 28,9\% dos entrevistados no Brasil, os serviços públicos de saúde prestados pelo SUS são muito bons ou bons. Proporção semelhante dos entrevistados (28,5\%) opinou que esses serviços são ruins ou muito ruins, enquanto $42,6 \%$ os consideraram regulares. Contudo, observa-se que existem diferenças quando se compara a percepção sobre os serviços públicos de saúde prestados pelo SUS, de maneira geral, entre os entrevistados que relataram ter utilizado ou acompanhado alguém de sua família na utilização de pelo menos um dos serviços pesquisados e aqueles que declararam não ter utilizado serviços do SUS. Entre os primeiros, ou seja, aqueles que tiveram alguma experiência com os serviços do SUS nos últimos doze meses, a proporção de opiniões de que os serviços são muito bons ou bons foi maior (30,4\%) do que entre os segundos (19,2\%). Por outro lado, a proporção de opiniões de que os serviços prestados pelos SUS são ruins ou muito ruins foi maior entre os entrevistados que não tiveram experiência com algum dos serviços pesquisados (34,3\%), em comparação com aqueles que tiveram ( $27,6 \%$ ). Não obstante, em ambos os grupos predominam as avaliações dos serviços como regulares". 


\section{Caso 4}

C. tem 33 anos. É casada pela segunda vez e mãe de quatro filhas. Mora com os pais e mais um irmão em uma residência própria. Filha de mãe empregada doméstica e pai auxiliar de pedreiro, C. trabalhava, no momento da entrevista, como profissional do sexo num salâo de massagem, o que é para ela uma fonte de angústia e ao mesmo tempo da renda de que ela precisa para sustentar as quatros filhas, já que o marido se encontrava desempregado.

Entrevistador: "Você conhece o Bolsa Família?"

Entrevistado: “Conheço. Eu recebo. Eu ganhei o Minha Casa Minha Vida.”

Entrevistador: "O que você acha desses programas assistenciais?"

Entrevistado: "Eu acho ótimo, né? É bom. Gostei. Vivo em uma das [unidades do] Minha Casa Minha Vida, pelo menos foi um jeito bom de empregar o dinheiro do povo, já que é do povo mesmo, né? E dizer assim, 'que o povo não quer mais trabalhar porque vive de Bolsa Família', é mentira. Porque ninguém vive com duzentos reais, com trezentos reais, não tem nada a ver, é um jeito de ajudar, e eu acho bom. Favorece muito a população pobre. Eu acho que ainda precisava de mais, favorecer mais porque dinheiro do povo guardado eles têm pra isso."

Entrevistador: "E nesses programas, você foi bem atendida?"

Entrevistado: "Fui bem atendida. Não vou mentir, não, teve tanta burocracia, não. Na minha parte, não. Foi tranquilo."

Como ilustra o caso 4, uma trajetória de relativa estabilidade na pobreza (casa própria, pais empregados etc.), apesar dos riscos e das vulnerabilidades enfrentadas, vai ao encontro de uma vinculaçáo positiva com as políticas de serviços públicos. A percepção é que há um bom uso do dinheiro do povo, isto é, o devido retorno em termos de recursos de estabilização e proteção contra as adversidades da vida. Essa representação sobre as políticas e as ações do Estado vem acompanhada também do relato da experiência do encontro burocrático como algo tranquilo e sem maiores intercorrências.

\subsection{Situações de precariedade e usos positivos}

Finalmente, a última forma de construção de vínculo identificada por Siblot (2006) em seu estudo diz respeito às famílias em situaçóes de precariedade, para as quais os recursos de interconhecimento e a ajuda mútua se tornam cruciais nas relações com a administração. As trajetórias de estabilização fora da precariedade revelam, ao mesmo tempo, uma forte experiência de constrangimento em relação à administração e o domínio desse constrangimento graças à desenvoltura pessoal no trato com os agentes administrativos, devido a laços localmente estabelecidos.

No caso apresentado a seguir, percebe-se também a construção de uma vinculação positiva. Os serviços e as políticas públicas aqui são representados como promotores de dignidade e respeito para usuários e beneficiários. Essa representação específica da ação pública vem, igualmente, acompanhada da percepção do encontro burocrático como algo não problemático e até digno de agradecimento (a Deus e às pessoas encontradas nesse percurso). 


\section{Caso 5}

O. é uma senhora negra, viúva, mãe de três filhos, dos quais duas adolescentes, ambas grávidas. Mora de aluguel numa casa simples. Viveu durante dez anos na casa de uma família de classe média, onde trabalhava. No momento da entrevista, encontrava-se desempregada. Contou que há meses deixa currículos para trabalhos domésticos, de limpeza e em fábricas, mas sem sucesso. Tem vivido de bicos, faxinas e às vezes diarista, mas de maneira bem inconstante. Confessou que em momentos mais críticos sai para pedir esmola nas casas. Ela não conta com nenhum familiar na cidade onde vive.

Entrevistador: "Você acha que programas como o Bolsa Família, o Minha Casa Minha Vida ajudaram a resgatar a dignidade das pessoas?"

Entrevistado: "Ajudaram, sim... Eu acho que sim, e muito. Muito!"

Entrevistador: "Por que você acha que isso ajudou as pessoas a se sentirem mais respeitadas?"

Entrevistado: "Porque eram pessoas que... Eram pessoas que moravam em barraco, como eu tô lhe dizendo, tinha pessoas em barraco ali no satélite. Construíram, deram casa, deram apartamento, tá entendendo? Eu acho isso bonito. Eu acho bonito, é um trabalho muito bem feito. Tá entendendo? Pra sociedade. Quem diria que uma pessoa podia ter um Bolsa Família, um apartamento bem bonitinho pra morar? Dois quartos, sala, cozinha e banheiro. De primeira. Isso não existia.”

Entrevistador: "Nesses programas que você usa, como o Bolsa Família, o Minha Casa Minha Vida, o próprio SUS, você foi bem atendida, foi bem tratada pelos funcionários?”

Entrevistado: "Graças a Deus, mesmo porque esse Bolsa Família veio numa hora... Eu nunca tinha recebido, sempre quem recebia eram os avós deles [dos filhos], então, depois que eu 'peguei eles', foi tudo cortado. Então eu fui correr atrás de algum benefício pra mim. Pra eles, né? Porque eu digo pra mim, mas é pra dentro de casa. Então, assim, graças a Deus, encontrei pessoas...”

Entrevistador: "Que lhe atenderam bem?"

Entrevistado: “Graças a Deus.”

\section{CONSIDERAÇÕES FINAIS}

Assim como Siblot (2006) fez questão de ressaltar, não se trata de apresentar aqui uma tipologia exaustiva das relaçóes entre usuários de serviços e agentes da sua administração, mas de demonstrar, por meio de situaçóes concretas e experiências de vida, a importância do entrelaçamento entre as formas de vinculação e significação de experiências de encontro burocrático e a trajetória e o posicionamento social dos indivíduos e suas famílias. O domínio dos procedimentos administrativos e a experiência das relaçóes com instituiçóes que fornecem direitos podem ser entendidos e utilizados como recursos para manutenção de uma posição estável ou ascendente. Em contrapartida, a sensação de ter que "pedir esmolas" às instituiçóes ou de se submeter às suas condiçóes (e.g., espera, desconforto, baixa qualidade) alimenta um sentimento de rebaixamento que leva a distanciar o governo e os serviços públicos como pertencentes ao mundo dos outros, podendo ser traduzido de forma mais geral por ressentimento em relação às instituiçóes e às políticas.

Em suma, como afirma Siblot (2006), o esforço analítico requerido é o de trazer à luz os sentidos práticos do Estado e das suas políticas públicas, construídos diariamente por usuários em suas interaçóes 
com agentes representantes das instituiçóes. Esses sentidos práticos começam a ser visibilizados por meio da análise minuciosa de como valores e representaçóes políticas e morais implícitas e não verbalizadas passam a se associar com instituiçóes públicas e seus modos de operação. As formas de vinculação com políticas e serviços públicos revelam não apenas maneiras de se relacionar com o poder institucional mas, também, com o meio social. Ambas as maneiras "são constitutivas da percepção da posição ocupada nas relaçôes sociais: a hierarquia entre grupos ou classes sociais e a relação com o poder institucional aparecem, assim, fortemente vinculadas" (Siblot, 2006, p. 15).

Por se tratar de estudo ainda em andamento, não é possível tirarmos conclusóes fortes. Os resultados iniciais da análise, no entanto, têm indicado que as hipóteses relacionadas a trajetórias e posiçóes sociais com as representaçóes construídas a partir das experiências de encontros burocráticos se apresentam como profícuas. Um mapeamento mais aprofundado e sistemático das trajetórias e das experiências de encontros burocráticos poderá render elementos importantes para reflexóes sobre os efeitos dessas confluências sobre o sentido de valor e localização social dos sujeitos, assim como sobre as representaçóes que constroem sobre o Estado e suas políticas públicas. Trata-se de questáo que integra a agenda de pesquisa desenvolvida pela Diest/Ipea nos últimos anos, centrada na compreensão dos riscos de reprodução de desigualdades em processos de implementação de políticas públicas (Pires, 2019).

\section{REFERÊNCIAS}

BLUMER, H. Symbolic interactionism: perspective and method. Englewood Cliffs: Prentice-Hall, 1969. BOURDIEU, P. Esquisse d'une théorie de la pratique. Genebra: Librairie Droz, 1972.

CROZIER, M. Le phénomène bureaucratique. Paris: Seuil, 1963.

CROZIER, M.; FRIEDBERG, E. L'acteur et le système. Paris: Seuil, 1977.

DUBOIS, V. La vie au guichet: relation administrative et traitement de la misère. Paris: Economica, 1999. DUPUY, F.; THOENIG, J.-C. Sociologie de l'administration française. Paris: Armand Colin, 1983. ELIAS, N. A sociedade dos indivíduos. Rio de Janeiro: Jorge Zahar Editora, 1994.

FRIEDBERG, E. L'analyse sociologique des organisations. Paris: GREP, 1972.

GOFFMAN, E. Encounters: two studies in the sociology of interaction. Indianapolis: Bobbs-Merrill, 1961.

GOODSELL, C. T. The public encounter: where state and citizen meet. Bloomington: Indiana University Press, 1981.

HASENFELD, Y. People processing organizations: an exchange approach. American Sociological Review, v. 37, n. 3, p. 256-263, 1972.

- Citizens' encounters with welfare state bureaucracies. Social Service Review, v. 59, n. 4, p. 622-635, Dec. 1985.

HASENFELD, Y.; RAFFERTY, J. A.; ZALD, M. N. The welfare state, citizenship, and bureaucratic encounters. Annual Review of Sociology, v. 13, n. 1, p. 387-415, 1987. 
HUGHES, E. The sociological eye: selected papers. New Brunswick: Transaction Books, 1971.

JOBERT, B.; MULLER, P. L'Etat en action, politiques publiques et corporatismes. Paris: PUF, 1987.

KAHN, R.; KATZ, D.; GUTEK, B. Bureaucratic encounters - an evaluation of government services. The Journal of Applied Behavioral Science, v. 12, n. 2, p. 178-198, 1976.

PIOLA, S. et al. SIPS saúde: percepção social sobre a saúde no Brasil. In: SCHIAVINATTO, F. (Org.). Sistema de Indicadores de Percepçáo Social (SIPS). Brasília: Ipea, 2011. p. 79-103.

PIRES, R. R. C. Sociologia do guichê e implementação de políticas públicas. Revista Brasileira de Informação Bibliográfica em Ciências Sociais, n. 81, p. 5-24, 2017.

. Implementando desigualdades: reprodução de desigualdades na implementação de políticas públicas. Rio de Janeiro: Ipea, 2019.

SHARMA, A.; GUPTA, A. The anthropology of the state: a reader. Malden: Blackwell Publishing, 2006.

SIBLOT, Y. Faire valoir ses droits au quotidien: les services publics dans les quartier populaire. Paris: Presses de la Fondation Nationale des Sciences Politiques, 2006.

SPIRE, A. Accueillir ou reconduire: enquete sur les guichets de l'immigration. Paris: Raisons d'Agir, 2008.

THOENIG, J.-C. L’ère des technocrates. Paris: Éditions d’Organisation, 1973. 
